\title{
O INÍCIO DE OPERAÇÃO DO ALTO-FORNO 2 DA VSB*
}

\author{
Paulo César Lemes de Almeida ${ }^{1}$ \\ Ronnie Lima de Souza ${ }^{2}$ \\ Aline Miranda Pessoa Passagli ${ }^{3}$ \\ Flávio Edmundo dos Anjos ${ }^{4}$ \\ Onídio Teixeira Pinto Júnior ${ }^{5}$ \\ Victor Freire de Oliveira ${ }^{6}$ \\ André Cabral de Oliveira ${ }^{7}$
}

\section{Resumo}

O Alto-forno 2 da VSB, na Usina de Jeceaba - MG, Brasil possui volume útil de $350 \mathrm{~m}^{3}$. Entrou em operação em 24 de julho de 2014 . Utiliza $100 \%$ de carvão vegetal como carga redutora. Nesta contribuição técnica é apresentado o planejamento para o início de operação, destacando-se o enchimento do alto-forno, a distribuição de carga e a preparação da área de corrida. São mostrados os resultados alcançados no primeiro mês de operação.

Palavras-chave: Alto-forno; Start-up; VSB; Carvão vegetal.

\section{Abstract}

\section{THE START-UP OF VSB BLAST FURNACE NR 2}

VSB Blast furnace $\mathrm{Nr} 2$ designed with a working volume of $350 \mathrm{~m}^{3}$ started its operation in $24^{\text {th }}$ July, 2014. VSB Works is located in Jeceaba, Minas Gerais, Brazil. The Blast furnace $\mathrm{Nr} 2$ is fuelled with charcoal. In this paper the blast furnace start-up planning is presented focusing on the blast furnace initial burden materials, burden distribution and cast house preparation. The results of the first month of operation are also presented.

Keywords: Blast furnace; Start-up; VSB; Charcoal.

1 Engenheiro Metalurgista, Engenheiro do Controle de Processo do alto-forno, VSB, Jeceaba, MG, Brasil.

2 Engenheiro Metalurgista, Coordenador do alto-forno, VSB, Jeceaba, MG, Brasil.

3 Engenheira de Produção, Coordenadora do Controle de Processo do alto-forno, VSB, Jeceaba, MG, Brasil.

4 Engenheiro Metalurgista, Coordenador das matérias-primas do alto-forno, VSB, Jeceaba, MG, Brasil.

5 Engenheiro Metalurgista, Gerente do alto-forno, VSB, Jeceaba, MG, Brasil.

6 Engenheiro Químico, Engenheiro de Projetos, Tecnologia/Processos, Paul Wurth do Brasil, Belo Horizonte, MG, Brasil.

7 Analista de Sistemas, Coordenador, Marketing \& Vendas, Paul Wurth do Brasil, Belo Horizonte, MG, Brasil. 


\section{INTRODUÇÃO}

A Vallourec Sumitomo Tubos do Brasil, VSB, possui uma usina integrada, destinada à produção de tubos sem costura, localizada em Jeceaba - MG. No projeto desta usina estão contemplados dois altos-fornos a carvão vegetal de $350 \mathrm{~m}^{3}$ de volume útil e capacidade nominal de $840 \mathrm{t} /$ dia cada, projetados pela Paul Wurth do Brasil. O alto-forno 1 ainda aguarda condições de mercado para finalizar sua montagem; já o alto-forno 2 (AF-2) teve sua montagem concluída; estando pronto para o início de operação no final de 2011, mas a retração do mercado siderúrgico levou o início da operação para 24 de julho de 2014. A figura 1 mostra uma visão completa da área do alto-forno da VSB.

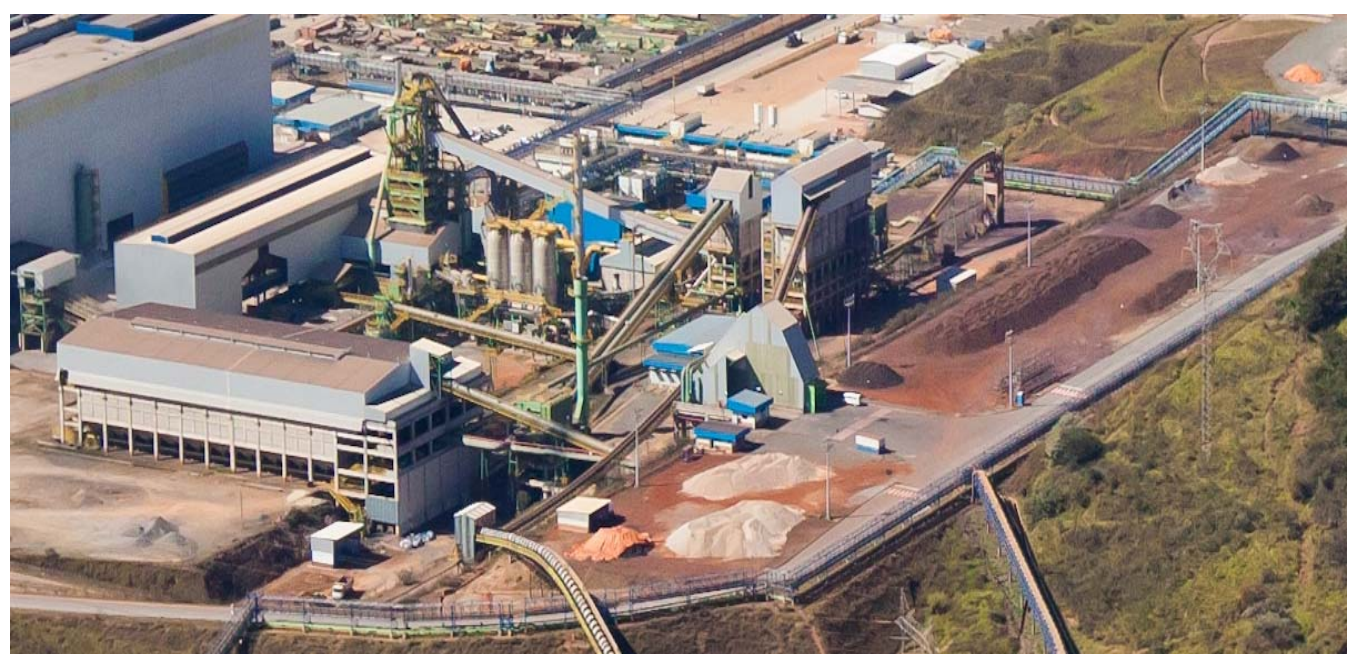

Figura 1 - Vista da área do alto-forno da VSB.

O objetivo da presente contribuição técnica é o de apresentar os principais aspectos do início de operação do AF-2 da VSB.

\section{MATERIAIS E MÉTODOS}

Todo início de operação de um alto-forno exige uma série de cuidados especiais, sendo [1]:

- elevar lentamente a vazão de sopro até a vazão operacional, onde se garantirá a velocidade de ar nas ventaneiras, formação das zonas de combustão e fusão;

- elevar a temperatura do gusa até a primeira corrida;

- obter gusa e escória com temperatura e fluidez adequadas nas primeiras corridas;

- período de aprendizado dos equipamentos e resposta do reator;

- segurança operacional inicial de forma a garantir uma campanha longa.

Para atender a esses objetivos é necessária a realização de um planejamento detalhado, visando um plano de enchimento bem elaborado, onde se determina:

- base de carvão para o enchimento;

- distribuição da relação carga metálica/carbono de enchimento;

- qualidade da escória;

- plano de cargas por regiões do alto-forno;

- teste de distribuição de carga; 
- $\quad$ plano de variáveis para processo: vazão, temperatura e pressão;

- previsão e plano de primeira corrida.

Foi realizado um comparativo dos altos-fornos com perfis mais semelhantes ao altoforno 2 da VSB, com vista a verificar os planejamentos de inicio de operação, sendo utilizado como referência o alto-forno 1 da APERAM e os altos-fornos 1 e 2 da VBR - Vallourec Brasil.

\section{RESULTADOS E DISCUSSÃO}

\subsection{Planejamento}

O plano para o início de operação (start-up) do AF-2 compreendeu:

- enchimento do cadinho do alto-forno com atiço (atiço: madeira que não foi totalmente carbonizada) ;

- enchimento do alto-forno propriamente dito;

- acendimento (blow-in) propriamente dito;

- preparação de áreas auxiliares tais como: área de corrida, sistema de limpeza de gases, sistema de sopro e regeneradores, ponte rolante, máquina de lingotar gusa e sala de controle.

\subsection{Enchimento do AF-2}

Para o enchimento do alto-forno, foram feitas as seguintes considerações:

- carregamento de atiço no cadinho;

- cargas secas (cargas feitas somente com carvão) com carvão vegetal > 32 $\mathrm{mm}$;

- relação M/C (minério/carvão) de 0,60;

- carga metálica constituída por $80 \%$ de pelota e $20 \%$ de minério de ferro granulado;

- base de carbono de $4.000 \mathrm{~kg} / \mathrm{carga}$;

- $\quad$ volume da carga seca corresponde a $40 \%$ do volume total das cargas;

- 14 cargas para enchimento do alto-forno;

- altura do carvão vegetal na goela de $1,79 \mathrm{~m}$ e no ventre de $0,90 \mathrm{~m}$.

Salienta-se que a pelota utilizada é produzida na própria VSB, o minério de ferro granulado é fornecido pela Vallourec Mineração e o carvão vegetal pela Vallourec Florestal.

No plano de enchimento adotou-se a divisão do alto-forno em regiões imaginárias, com volumes calculados para definição do número de cargas, conforme mostrado na figura 2.

\subsection{Distribuição de Carga}

O AF-2 é equipado com sistema de topo SBPT (Single Bell Pressure Top) e distribuição de carga por placas defletoras móveis, com seis posições pré-definidas. Em dezembro de 2012, foram realizados testes simulando a distribuição de carga no AF-2. Foi instalada uma plataforma no topo do alto-forno para a coleta das matériasprimas utilizadas no teste. Foram testadas diferentes combinações de matériasprimas e posições das placas defletoras. 


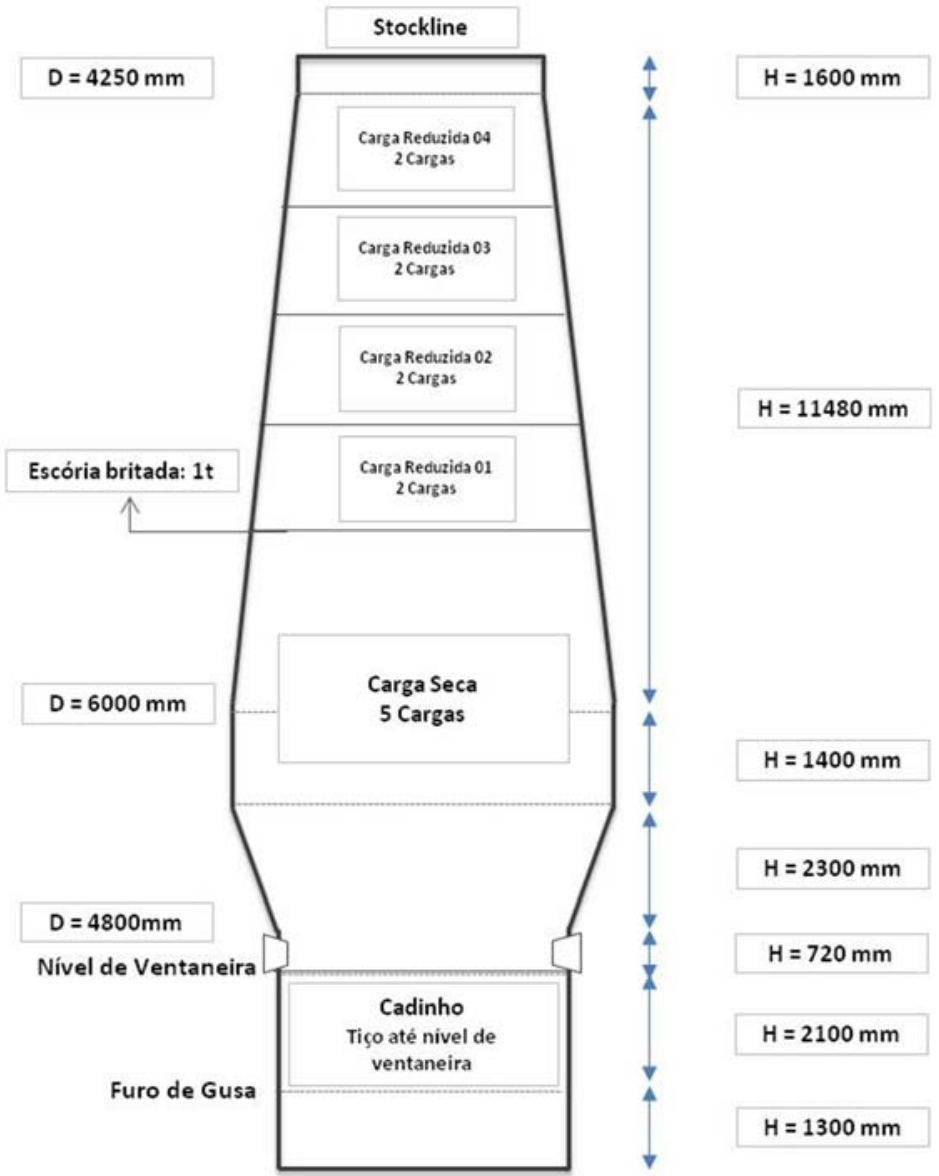

Figura 2 - Desenho esquemático do alto-forno mostrando as diferentes cargas do enchimento.

Para definir a sequência inicial de carregamento do alto-forno para o start up foram utilizados os resultados dos testes. A figura 3 exemplifica como é a visualização da distribuição de carga para a sequência adotada.

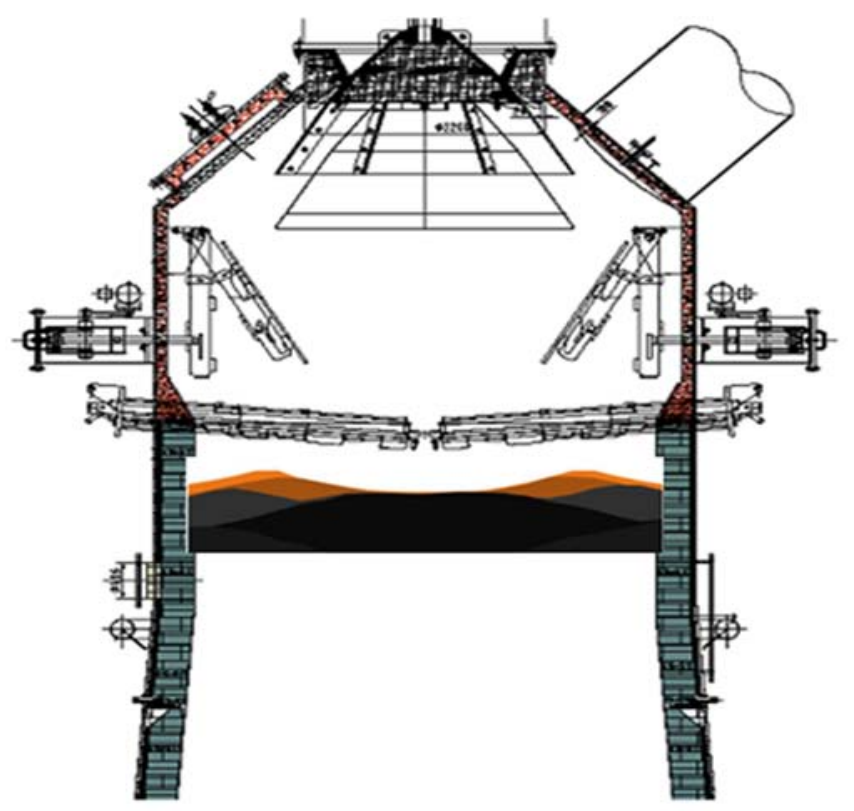

Figura 3 - Figura esquemática da distribuição de carga adotada no início de operação do alto-forno 2. 
A posição 6 das placas móveis é a mais avançada e a posição 0 é a mais recuada. $\mathrm{Na}$ tabela 1 é apresentada a sequência de carregamento (CCMM) utilizada no início de operação do AF-2.

Tabela 1 - Sequência inicial de carregamento do AF-2

\begin{tabular}{c|c}
\hline Matéria-prima & $\begin{array}{c}\text { Posição da } \\
\text { placa móvel }\end{array}$ \\
\hline carvão grosso & 6 \\
\hline carvão médio & 0 \\
\hline carga metálica & 2 \\
\hline carga metálica & 0 \\
\hline
\end{tabular}

\subsection{Colocação do Gás de Alto-forno na Rede da Usina}

Para realizar a gaseificação do sistema de gás de alto-forno (GAF) duas condições devem ser obedecidas rigorosamente:

- teor de oxigênio inferior a 0,2\% (razão: não ter comburente suficiente evitando risco de explosão);

- $\quad$ teor de hidrogênio inferior a 10\% (razão: não ter risco do gás inflamar);

- ambas as condições devem ser atendidas.

Como as válvulas bleeders estão abertas, um ponto de coleta do gás situa-se na tubulação do topo (uptakes) e um tubo conecta este ponto ao local onde é coletada a amostra de GAF. Outro ponto de coleta está na saída do coletor de pó. As amostras de GAF são enviadas ao laboratório químico, onde são analisadas via ORSAT. A figura 4 mostra o início de operação do AF2 antes de colocar o gás na rede.

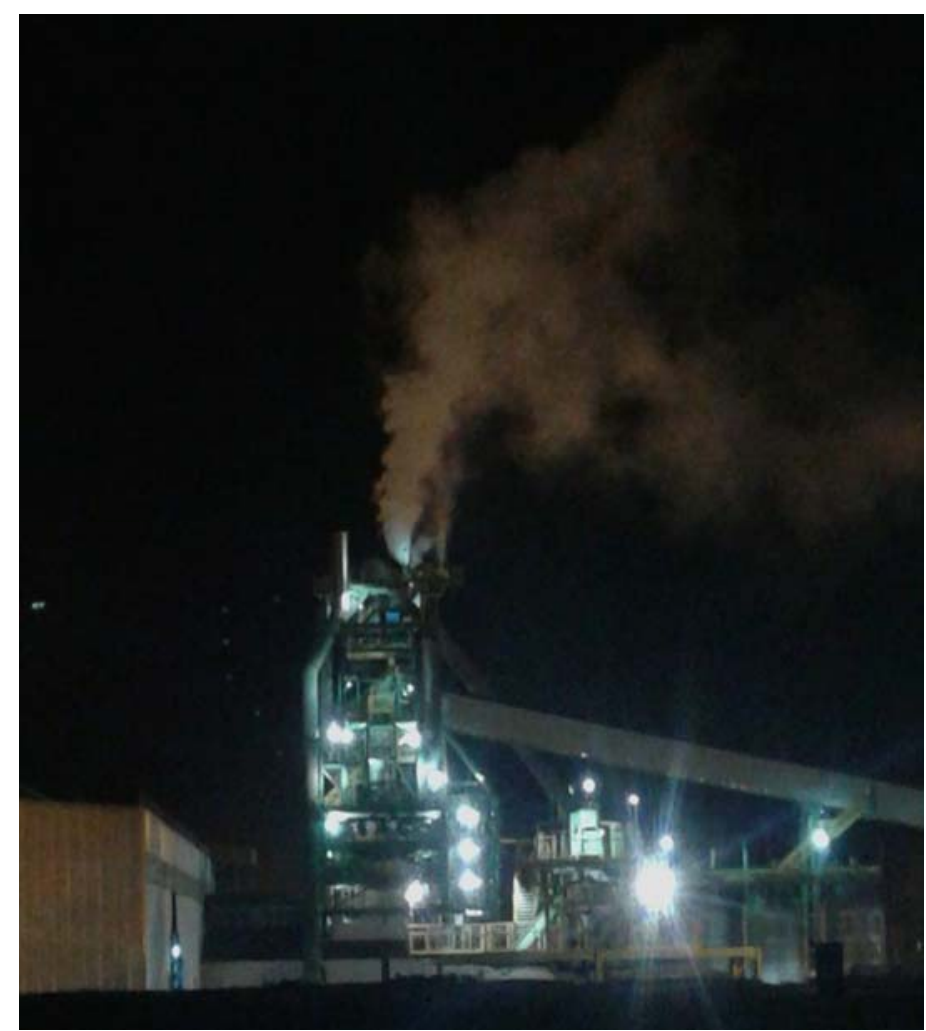

Figura 4 - Início de operação do AF2 VSB antes de colocar o gás na rede. 


\subsection{Evolução dos Parâmetros Operacionais}

O início de operação do AF-2 da VSB teve como principais eventos iniciais, em ordem cronológica:

\section{4-julho-2014:}

- 02h29: blow-in;

- 06h00: normalização do carregamento;

- 07h00: gás de alto-forno disponibilizado na rede da Usina;

- 11h00: iniciada a refrigeração do cadinho;

- 12h40: início de operação dos regeneradores ("cowpers");

- 16h00: enfornada $1^{\mathrm{a}}$ carga com consumo específico de carbono de $577 \mathrm{~kg} / \mathrm{t}$;

- 20h00: corte do tubo do blow-in;

\section{5-julho-2014:}

- 04h24: $1^{\mathrm{a}}$ corrida;

\section{6-julho-2014:}

- 01h30: $1^{\mathrm{a}}$ corrida lingotada (corrida 07).

A figura 5 mostra o momento em que ocorreu a primeira corrida de gusa do AF2 da VSB.

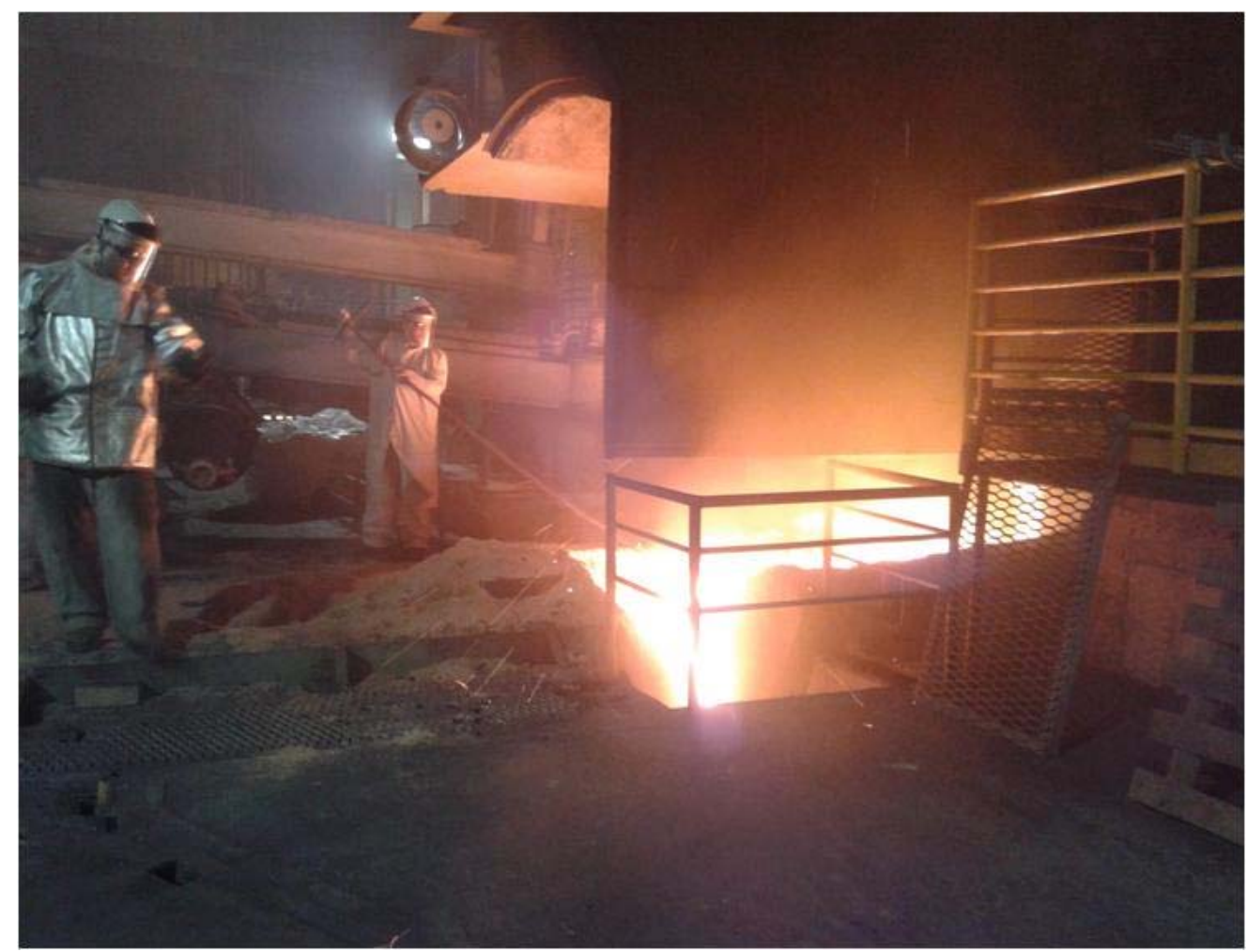

Figura 5 - $1^{\text {a }}$ corrida do AF2 realizada no dia 25 de julho de 2015.

A seguir comenta-se a evolução dos principais parâmetros operacionais do AF-2 da VSB no primeiro mês de operação.

\subsubsection{Produção de gusa}

A figura 6 apresenta a evolução da produção diária nos primeiros dias de operação. 


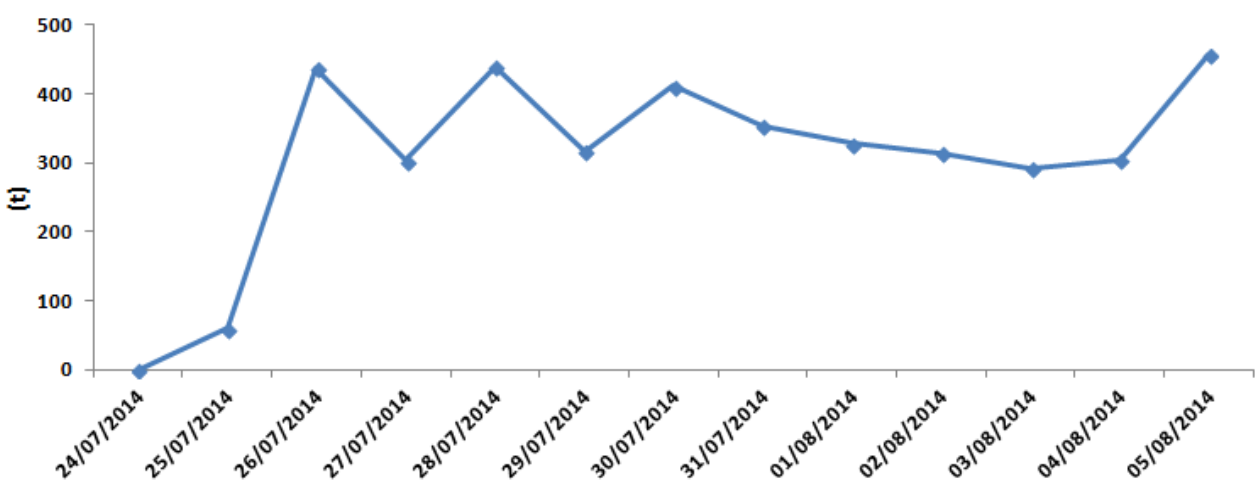

Figura 6 - Produção diária do AF2 nos primeiros dias de operação.

Como se pode perceber na figura 6 , a produção atinge um patamar de 400 t/dia já no segundo dia de operação. Salienta-se que o gusa é transportado para a aciaria ou máquina de lingotar por panelas.

Nos dias 7 e 8 de agosto foi realizada a primeira parada programada do alto-forno, com o intuito de resolver pendências identificadas nos primeiros quinze dias de operação. Após essa parada, objetivou-se ritmo de produção de 600 t/dia, em virtude do cenário de produção da usina.

\subsubsection{Parâmetros relacionados ao sopro}

A figura 7 apresenta a evolução da vazão de sopro nas primeiras horas de operação.

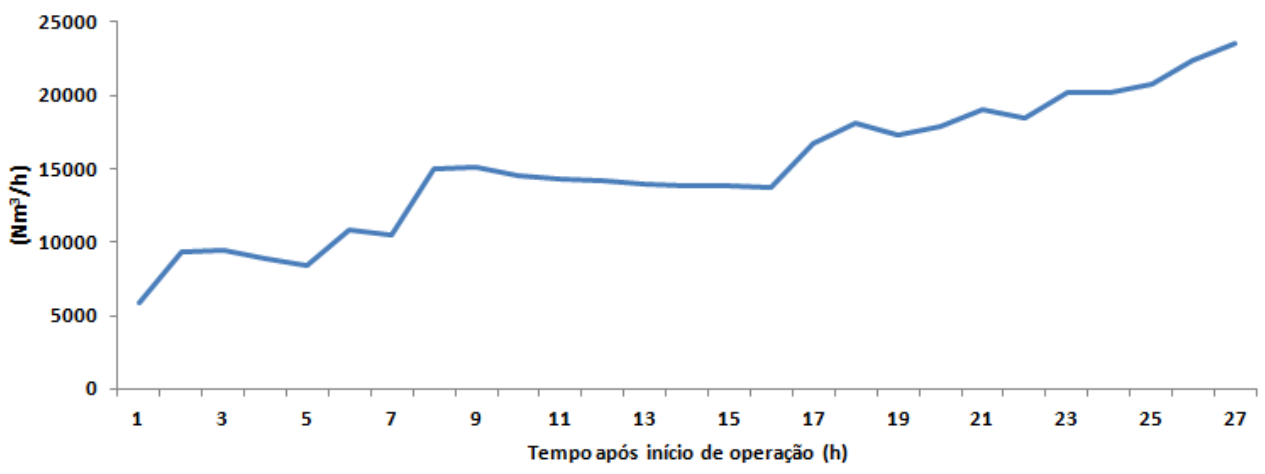

Figura 7 - Evolução da vazão de sopro nas primeiras horas de operação.

O AF-2 iniciou as primeiras horas de operação com a vazão de sopro em 10.000 $\mathrm{Nm}^{3} / \mathrm{h}$ e manteve essa vazão até que o gás de alto-forno fosse disponibilizado na rede. Depois de cumprida essa etapa elevou-se a vazão para $15.000 \mathrm{Nm}^{3} / \mathrm{h}$ e foi mantida nesse patamar por aproximadamente 9 horas, com o objetivo de aquecer 0 revestimento refratário e formação de zonas especificas no alto-forno. Em seguida, deu-se sequência ao plano de elevação da vazão de sopro.

As figuras 8 e 9 apresentam a evolução da vazão de sopro e do índice de permeabilidade nos primeiros dias de operação. 


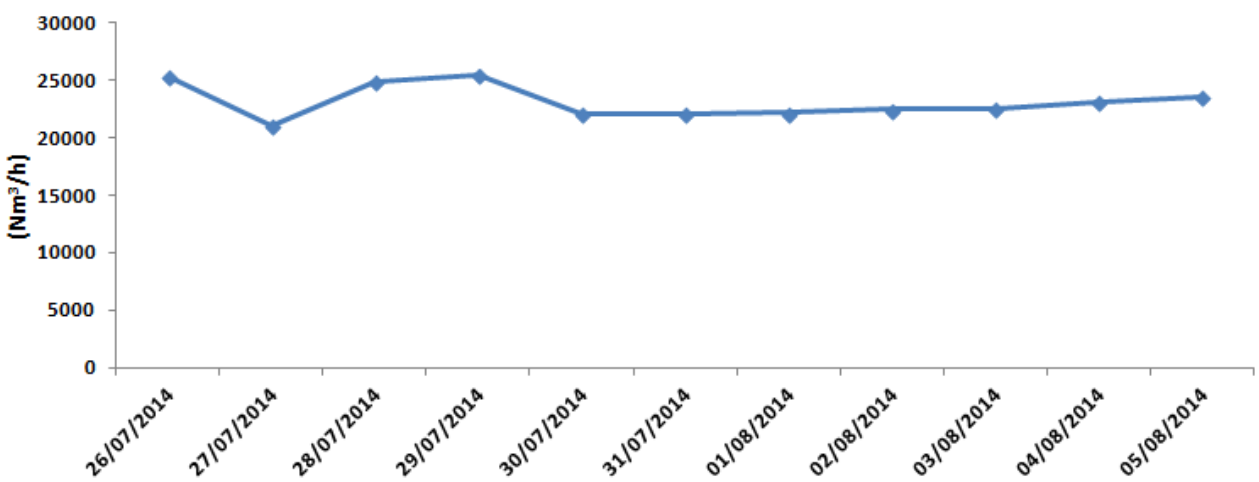

Figura 8- Evolução diária da vazão de sopro.

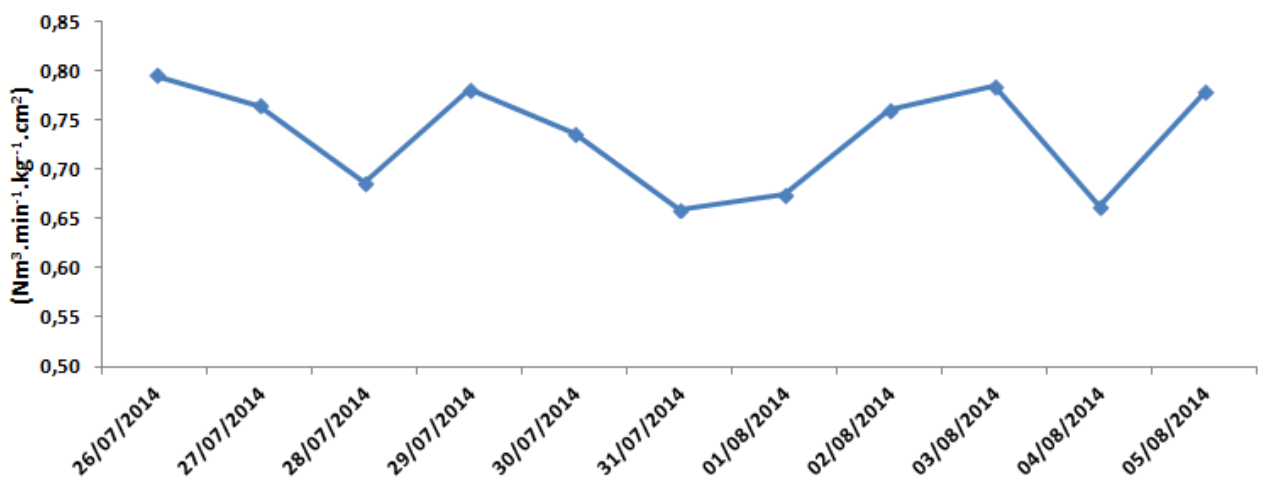

Figura 9 - Evolução diária do índice de permeabilidade.

Nos primeiros dias de operação do AF-2 não foi possível realizar medição da temperatura de sopro, em virtude do posicionamento do termopar no duto de ar quente. Essa foi uma das pendências normalizadas na primeira parada programada, após quinze dias de operação para revisão geral dos equipamentos.

\subsubsection{Consumo de redutor e injeção de carvão pulverizado}

Até a entrada da injeção de carvão pulverizado, operou-se com consumo de carbono da ordem de $500 \mathrm{~kg} / \mathrm{t}$.

O início de operação da unidade de injeção de carvão pulverizado (ICP) foi após a primeira parada programada. A partir do dia 31 de agosto de 2014, trabalhou-se com a taxa de injeção de $120 \mathrm{~kg} / \mathrm{t}$.

\subsubsection{Qualidade do gusa e escória}

As figuras 10 e 11 apresentam a evolução da temperatura e do teor de silício do gusa nos dois primeiros dias de operação. 


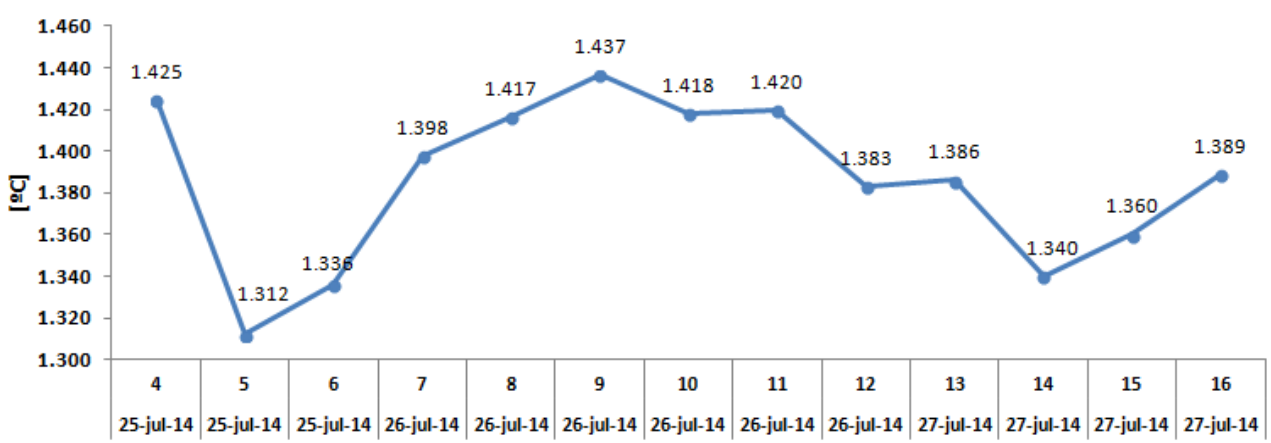

Corrida | Data

Figura 10 - Evolução da temperatura do gusa.

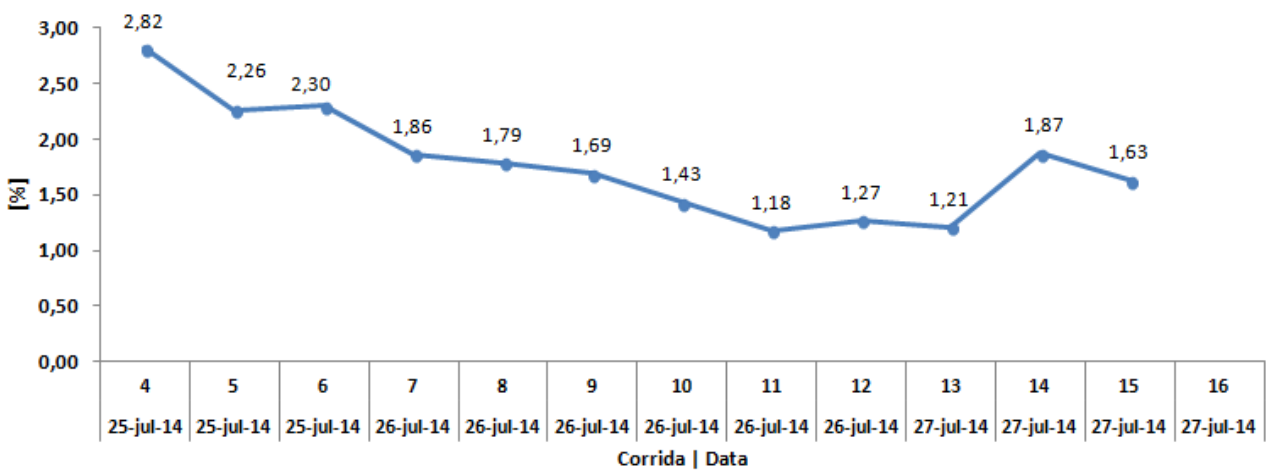

Figura 11 - Evolução do teor de silício no canal.

Nas primeiras corridas, devido ao consumo específico de carbono elevado e vazão reduzida, o teor de silício do gusa permaneceu em patamar próximo a 1,20\%. Após a primeira parada programada, com o início da injeção de carvão pulverizado, o controle do nível térmico do alto-forno ficou mais estável e, por consequência, conseguiu-se teor de $\mathrm{Si}$ abaixo de 0,80\%. A tabela 2 apresenta os critérios de aceitação do gusa líquido pela aciaria e a tabela 3 apresenta os principais parâmetros relativos à escória. Esses parâmetros foram determinados visando a atender temperatura "liquidus" e viscosidade.

Tabela 2 - Composição química objetivada do gusa líquido para atendimento à aciaria.

\begin{tabular}{l|c|c}
\hline \multicolumn{1}{c|}{ Parâmetro } & Faixa objetivada & Faixa de aceitação \\
\hline$\% \mathrm{Si}$ & $\leq 0,80$ & $\leq 1,20$ \\
$\% \mathrm{Mn}$ & $\leq 0,50$ & $\leq 0,60$ \\
$\% \mathrm{P}$ & $\leq 0,100$ & $<0,120$ \\
\hline
\end{tabular}

Tabela 3 - Principais parâmetros da escória.

\begin{tabular}{c|c|c}
\hline Parâmetro & Unidade & Faixa \\
\hline Volume de escória & $\mathrm{kg} / \mathrm{t}$ & $140-170$ \\
\hline Teor de $(\mathrm{MgO})$ & $\%$ & $8-10$ \\
\hline $\begin{array}{c}\text { Índice de basicidade } \\
\text { binária: }(\mathrm{CaO}) /\left(\mathrm{SiO}_{2}\right)\end{array}$ & $* * *$ & $0,60-0,70$ \\
\hline $\begin{array}{c}\text { Índice de basicidade } \\
\text { ternária: } \\
(\mathrm{CaO}+\mathrm{MgO}) /\left(\mathrm{SiO}_{2}\right)\end{array}$ & $* * *$ & $0,75-0,85$ \\
\hline
\end{tabular}




\subsection{Avaliação do Start-up}

A tabela 4 ressalta os principais pontos positivos e de melhoria identificados nos primeiros dias de operação do Alto-forno 2.

Tabela 4 - Avaliação do start-up.

\begin{tabular}{|c|c|}
\hline Pontos positivos & Pontos de melhoria \\
\hline $\begin{array}{l}\text { - } \text { zero acidente; } \\
\text { realização prévia de testes com carga } \\
\text { nos principais equipamentos garantiu um } \\
\text { start-up sem ocorrência de parada } \\
\text { emergencial; } \\
\text { - } \quad \text { ausência de problemas com a qualidade } \\
\text { das matérias-primas; } \\
\text { - confiabilidade nos resultados de análise } \\
\text { química e ensaios físicos de matérias- } \\
\text { primas, gusa e escória; } \\
\text { - consumo de carvão bruto conforme } \\
\text { planejado; } \\
\text { realização das reuniões técnicas de } \\
\text { - gavaliação de processo; } \\
\text { - gestão de quase-acidentes e desvios; } \\
\text { integração da equipe. }\end{array}$ & $\begin{array}{l}\text { - logística e limpeza das panelas de gusa; } \\
\text { - máquina de lingotar gusa: práticas } \\
\text { - } \text { operacionais e plano de manutenção; } \\
\text { - curva de aprendizado do uso de gusa } \\
\text { líquido na aciaria: } \\
\text { - ajustes na especificação do gusa; } \\
\text { - teor de Si e temperatura do } \\
\text { gusa; } \\
\text { - redução de contaminação do gusa } \\
\text { sólido; }\end{array}$ \\
\hline
\end{tabular}

\section{CONCLUSÃO}

As principais conclusões são:

- atendimento aos itens de segurança com zero acidente;

- confiabilidade do equipamento traduzida pela ausência de paradas emergenciais;

- os principais parâmetros operacionais do alto-forno atenderam ao planejado.

\section{Agradecimentos}

Os autores agradecem aos consultores Raimundo Braga, Jadir Cruz, Ronaldo Sampaio e José Batista Vieira pelo grande apoio recebido e ressaltam a colaboração das equipes de operação, manutenção e apoio para o atingimento do sucesso do start-up.

\section{REFERÊNCIAS}

1 Sarmento ACM. Fabricação de ferro-gusa em altos-fornos a carvão vegetal.Curso ABM. São Paulo. ABM. 2007. 